therefore be combined with mosquito reduction when the malaria-frequency is high.

Dr. C. A. Bentley has published a very good report on malaria in Bombay and its prevention. He concludes that, as was manifest from the first, the principal measure must be the reduction of the carrier, $N$. stephensi. The cost should be about 1oo,00o rupees a year. Our studies of malaria are, then, advancing into fine detail; but I agree with Colonel King, C.I.E., that practical preventive measures should not be postponed until we actually become quite omniscient. That will imply a considerable loss of life in the meantime. We have already waited twelve years in India.

\section{R. Ross.}

\section{THE LONGEVITY OF ANIMALS. ${ }^{1}$}

$\mathrm{NE}$ of the most satisfactory results of the reorganisation of the Zoological Society of London is the series of papers dealing with important aspects of animal life which are now issuing from the pens of the society's officials. Instead of being content to amass, as formerly, a mere collection of as many strange beasts as possible for the inspection of the idle and curious, the officials are now directing their attention to many important points concerning the life of animals which could not have been examined, except where such unrivalled opportunities exist for their prosecution. Thus the Gardens bid fair to become a centre for important studies, while the health of the animals improves as the results are brought to bear on their treatment and housing.

In a recent paper Dr. Chalmers Mitchell has collected the available information supplied by records in the Gardens concerning the length of life and viability of mammals and birds.

On first glancing at this paper we are struck by the immense amount of information collected, and, on the other hand, by the small amount of knowledge which we really possess on so important a subject.

This deficiency is not likely to be easily eliminated, since our powers of ascertaining the actual length of life of any wild animal are, and must always remain, strictly limited. Sometimes an individual animal becomes abnormally marked, so that we observe and watch it for a period, or the unnatural life of a captive affords us material for estimating the longevity of the wild race; but such isolated observations can at the best only be regarded as approximate, and our knowledge of the longevity of the bulk of wild animals must always remain meagre.

Even our knowledge of the longevity of common domestic animals is far below the standard which might be expected. Domestic fowls are said by Dr. Mitchell to be capable of living for thirty years, yet, owing to commercial reasons, few members of the farmyard flock reach five years. It is the same with cattle. Although their potential longevity is, according to Dr. Mitchell, about thirty years, we habitually kill all our beef cattle and bulls under five, and a vast majority of our cows under twelve years. The same principle holds with all domestic breeds, the tendency being to speed up the processes of life to such an extent that the career of the organism is concluded at an artificially early date.

On the other hand, there are methods which may eventually yield a considerable increase of knowledge, and one of these is used by Dr. Mitchell, who has tabulated the numerous records kept in the prosectorium of the Zoological Society, and has calculated

1 "On Longevity and Relative Viability in Mammals and Birds : with a Note on the Theory of Longevity." By Dr. P. Chalmers Mitchell, F.R.S. Secretary to the Zoological Society of London. From th: Proc. Zool. Soc Lond., I911. Published June, IgrI.

NO. 2200 . VOL. 88$]$ the average and maximum longevity of a large number of mammals and birds which have lived and died in the Gardens. From these it appears that the average duration of life of any species in the Gardens is as a rule remarkably below the maximum duration, so that, to the majority of animals, captivity, even under the care of experts and in spite of the resulting protection from enemies, is anything but conducive to great length of life. Even, however, after allowing for the undoubted shortening of life resulting from captivity, the potential longevity of mammals in general appears to be surprisingly low, and it may be some satisfaction to know that the possible duration of life in man is probably greater than that of any other mammal, excepting, possibly, the large whales.

In this respect birds seem to be fully equal, if not superior, to mammals, amongst which those who live longest are certain of the larger carnivora and ungulates. For instance, the potential longevity of lions is between thirty and forty years; a polar bear lived to thirty-three years in the Gardens, and the largest ungulates may reach fifty years.

Both whales and elephants are popularly supposed to be creatures of high potential longevity, but as regards the former, the officials of the Zoological Gardens are naturally not in a position to offer any information. As regards the latter, it appears that their reputation has been wrongly acquired, since for them Dr. Mitchell estimates one hundred years as being the probable limit, and twenty to thirty years a fair average duration. On the other hand, there are amongst birds several groups which equal or exceed such figures. A raven has been known to reach sixty-nine years, an eagle sixty-eight, while more than one parrot has been recorded to have survived to close upon or more than a century. It appears that some birds of prey may also reach Ioo, and that herons, swans, and geese have a high potential longevity. The ostrich, to judge by its size, ought to live as long as any other bird, but thirty-five years is considered to be an extreme age for it.

The most difficult mammals to keep in captivity are probably the insectivorous bats. For these the maximum duration of life in the Gardens has so far been only five months, but the failure to keep them alive is undoubtedly due, not to their being naturally shortlived animals, but to their great delicacy under artificial conditions.

These bats commence to breed at relatively so late a period of their life and produce so few young at a time or in any single season that the majority of them must in nature reach an age of at least five years, that is, if they are to keep up their numbers and without making any allowance for the undoubtedly high death-rate which is always prevalent amongst wild animals. Dr. Mitchell has calculated the deathrate for the London sparrows at at least 50 per cent. in a stationary population; in the mixed assemblance of vertebrates in the Zoological Gardens it has been observed to be 28 per cent., both of which figures are very much above that of human beings.

Weissman has sought to estahlish a correlation between longevity and reproduction, but Dr. Mitchell refuses to accept his interpretation. He believes, not that longevity has become adapted to reproduction, but that the rate of reproduction has been adapted to average specific longevity. In any case, the deathrate amongst prolific wild animals maintaining a stationary population must be stupendous; for instance, if a mouse produces only two litters a year of six young in each, then if all survive to maturity there will be fourteen mice where before there were only two, and if the population is to remain stationary 
twelve must die, and these figures may be regarded as probably below the mark where food is abundant.

The relative prolificacy of the rodents as compared with many of the carnivora which feed upon them does not come within the scope of Dr. Mitchell's paper, but it is a remarkable instance of the interrelation of the system of life upon our planet that those which are preyed upon should be on the whole more prolific than those which prey.

Possibly the shortest-lived mammals are to be found amongst the shrews, of which a solitary individual is tabled in Dr. Mitchell's records as having survived captivity for one month. Shrews are extremely difficut to keep alive under artificial conditions, and evidence has lately been produced to suggest that, in the case of the two commoner British species, the average duration of life is only about a year, but, since shrews are amongst the most prolific of mammals, this short period is more than sufficient for the maintenance of their numbers.

It appears that there is no rule which can be laid down in advance to govern the probable length of life of any given species. Size has very little to do with it, although in the same group the larger usually live longer than the smaller. The climate from which a bird or mammal comes has the smallest possible relation to its viability in captivity; in fact, not nearly so much influence as the nature of the cages, or enclosures, which the captive animal is to occupy, since Dr. Mitchell shows that a system of combining free access to open air with suitable dry shelters of small size offers the most ideal conditions for the health of captive animals. Strange to say, it is not animals from the tropics that suffer most from the London climate, but those from the Arctic, which seem to find a difficulty in altering the rhythm of their moults. Those from south temperate regions are even in a worse plight, since they have to face the fact that the conditions of winter and summer are reversed in the northern hemisphere.

A remarkable suggestion of Dr. Mitchell's is that animals from thickly populated countries are on the whole more difficult to keep alive in captivity than those from regions where men are less known. This applies especially to British birds, and Dr. Mitchell suggests that their lower viability in captivity in England, as compared with that of their immediate allies from any other part of the world, is probably due to their intolerance of man, without which unfortunately they would not have been able to maintain their existence as wild creatures.

\section{NOTES.}

ThE meeting of the All-India Malaria Committee of the Government of India at Bombay in November last marks a revolution in Indian sanitation. For years past the a revolution in Indian sanitation. For years past the nothing but quinine prophylaxis against malaria, and have not encouraged, or have even discouraged, mosquitoreduction-alarmed, apparently, at what appeared at first sight to be the cost of the latter measure. Owing, however, to constant discussions (in which NaturE has taken a part), another spirit has now shown itself. The conference passed a series of resolutions in which mosquitoreduction is at last recommended for India-years after it has been regularly employed elsewhere. This ultimately means the formation of a genuine sanitary service for the whole of India on the lines recently suggested by Sir R. Ross, Colonel King, and Dr. Simpson in The Times, and with the enthusiastic medical services which the Govern. ment has at its command we may expect great results in time. The Indian Press deals at length with the matter, NO. 2200 , VOL. 88 and the Madras Mail remarks: "It is just fourteen years since Sir Ronald Ross, working in India-at Secunderabad-discovered the method of transmission of the malaria parasite from man to man by the anopheline mosquito. Malaria causes more sickness and mortality than any other disease in India; yet, knowing all about its method of transmission for the last fourteen years, what has been done in the interval in the way of practical application of the knowledge furnished by Sir Ronald Ross? Nothing! Verily, a prophet is without honour in his own country. There is hardly another country but has something to show -often most brilliant results. Now that the admission has been made that India has hitherto been on the wrong track, we again express the hope that something of a practical nature will shortly be done to mitigate the ravages of malaria in this country."

Mr. George R. M. Murray, F.R.S., who died at Stonehaven on December I6, at fifty-three years of age, joined the Department of Botany of the British Museum in 1876 , after having spent some time in de Bary's laboratory at Strassburg. He thus started his work at the museum well equipped for the study of the fungi. Murray approached with characteristic enthusiasm the task assigned to him by his chief, Mr. Carruthers, of building up the cryptogamic herbarium. There in the great collections, especially of fungi and algæ, lies the chief record of his work for nearly thirty years. His earlier work was on the fungi, but later he turned to the algæ, and in association with younger workers whom he had attracted to the museum, published a series of papers on the structure and affinities of certain genera. A number of these papers were brought together in the "Phycological Memoirs," which he edited (I892-5). In I895 was published his "Introduction to the Study of Seaweeds," and in the same year he succeeded Mr. Carruthers as keeper of the Department of Botany. He next turned his attention to marine plankton, and accumulated a large amount of material, much of which he collected himself on various excursions on or across the Atlantic. He embarked on this new work with his usual energy and enthusiasm, but his scientific career was abruptly ended by a breakdown in health that necessitated his retirement. Murray's work was not limited to official duties. As a young man he was known as an able teacher and lecturer. He was for some time lecturer in botany at St. George's Hospital, and later at the Royal Veterinary College; and in conjunction with A. W. Bennett he brought out a text-book on cryptogamic botany. He was secretary to a committee which organised useful work of botanical exploration in the West Indies, and for some sessions he worked hard for his section at the British Association meetings. Until his health failed he was a keen supporter of the Linnean Society, serving on the council almost continuously from 1883 to 1900 . He was elected into the Royal Society in 1897 .

THE Board of Trade has been informed that the twelfth International Navigation Congress will be opened at Philadelphia on May 23, 1912, under the patronage of President Taft. Further particulars, including the conditions under which persons or corporations may participate in the congress, can be obtained from Lieut.-Colonel Sandford, general secretary of the congress, The Bourse, Room 344, Philadelphia, P.A. (U.S.A.).

THE death is announced, in his fifty-second year, of Mr. James Aitchison, who founded the business of Messrs. Aitchison and Co., opticians, about a quarter of a century ago, and as one of the founders of the Optical Society did much to promote study and research among members of 